Supporting Information

\title{
Projecting the Specific Energy of Rechargeable
}

\section{Zinc-Air Batteries}

Brandon J. Hopkins*, Christopher N. Chervin, Jeffrey W. Long, Debra R. Rolison, and Joseph F. Parker

\section{Corresponding Author}

* U.S. Naval Research Laboratory, National Research Council Postdoctoral Associate,

Surface Chemistry Branch, Code 6170, U.S. Naval Research Laboratory, Washington, DC 20375, USA

Email: brandon.hopkins.ctr@nrl.navy.mil

Table S1. Reported Zn-air cell data.

\begin{tabular}{lll}
\hline Discharge Voltage $(\mathbf{V})$ & Areal Capacity $\left(\mathbf{m A h} \mathbf{~ c m}_{\mathbf{g e o}}{ }^{-\mathbf{2}}\right)$ & Reference \\
\hline 1.00 & 20.0 & 11 \\
\hline 1.20 & 33.4 & 12 \\
\hline 1.25 & 50.0 & 13 \\
\hline 1.10 & 100.0 & 14 \\
\hline 1.19 & 125.0 & 15 \\
\hline 1.25 & 200.0 & 16 \\
\hline
\end{tabular}

